\title{
1 Binge eating behaviours and food cravings in women with Polycystic Ovary
}

2 Syndrome

3 Y. M. Jeanes ${ }^{1}$, S. Reeves ${ }^{1}$, E. L.Gibson ${ }^{2}$, C. Piggott ${ }^{1}$, V.A. May ${ }^{1}$, K. H. Hart ${ }^{3}$

4

$5 \quad{ }^{1}$ Health Sciences Research Centre, Department of Life Sciences and ${ }^{2}$ Clinical and Health

6 Psychology Research Centre, Department of Psychology, University of Roehampton, UK.

$7{ }^{3}$ Department of Nutritional Sciences, Faculty of Health and Medical Sciences, University of

8 Surrey, Guildford, Surrey, UK

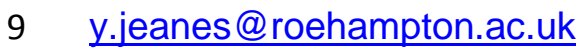

10 s.reeves@roehampton.ac.uk

11 l.gibson@roehampton.ac.uk

12 k.hart@surrey.ac.uk

14 Corresponding author:

15 Yvonne M Jeanes

16 y.jeanes@roehampton.ac.uk

17 Health Sciences Research Centre, Department of Life Sciences, University of Roehampton, 18 UK. 


\section{Abstract:}

Polycystic Ovary Syndrome (PCOS), the most common endocrine condition in women, is often anecdotally associated with binge eating behaviours and food cravings; however there is a paucity of research. This study aimed to report the prevalence of binge eating and food cravings and their relation to obesity risk in women with PCOS. Participants completed an online survey including the Bulimia Investigatory Test, Edinburgh, Food Cravings-Trait Questionnaire and the Three Factor Eating Questionnaire revised-18. The study included obese $(n=340)$, overweight $(n=70)$ and lean $(n=45)$ women with PCOS and lean healthy women $(n=40)$. Sixty percent of obese women with PCOS were categorised with bingeeating behaviour, with $39 \%$ presenting with clinically significant behaviour. Obese women with PCOS presented with high mean food cravings-trait scores (131.6 \pm 28.9$)$ that were

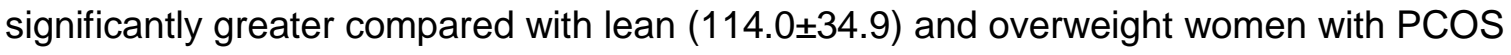
(120.1 $\pm 29.5 ; p<0.001)$. Multiple regression exploring relations between eating styles and adiposity explained $59 \%$ of the variance in binge eating symptom scores in women with PCOS ( $F=173.8 ; p<0.001, n=463)$ : significant predictors were food cravings total score (beta $=0.52 ; p<0.001$ ), emotional eating score (beta $=0.16 ; p<0.001)$, BMl (beta $=0.13$; $p<0.001$ ) and uncontrolled eating score (beta $=0.10 ; p<0.01$ ). Compared with lean healthy women, lean women with PCOS exhibited significantly higher binge eating symptom scores $(10.9 \pm 7.8$ versus $7.4 \pm 6.0 ; p<0.05)$, though similar total food craving scores $(114.0 \pm 34.9$ versus 105.6 \pm 26.6 : NS). This study is the largest, to date, to robustly report that a high proportion of women with PCOS exhibit binge eating behaviours. We recommend screening women with PCOS for binge eating behaviours to help inform the choice of weight management approach for this clinical population.

Key words: Polycystic ovary syndrome, Obesity, Binge eating, Food cravings, eating disorders

\section{Abbreviations:}

PCOS: Polycystic ovary syndrome 
Polycystic ovary syndrome (PCOS) is the most common endocrine condition in women, affecting up to $18 \%$ of women (1) and is characterised by a heterogeneous presentation of hyperandrogenism and ovulatory dysfunction. Women with PCOS have a greater insulin resistance, risk of developing type 2 diabetes (2), and a greater risk of being overweight and obese compared with healthy controls (BMI $>30$ RR 2.77 (95\% Cl 1.88 to 4.10) (3). Obesity significantly worsens all metabolic and reproductive outcomes for women with PCOS (4), though importantly as little as $5 \%$ weight loss has been shown to improve reproductive, metabolic and clinical markers $(5,6)$. Weight management through lifestyle modification is the first line treatment within international guidelines for the management of PCOS (7-11), although the effectiveness of such treatments is limited.

64

Binge eating has been shown to predict excess weight gain (12), obesity onset (13), weight regain after dieting (14) and failed weight loss (15). Binge eating behaviour is characterized by: (i) eating, in a discrete period of time, an amount of food that is definitely larger than most people would eat in a similar period of time under similar circumstances; and (ii) a sense of lack of control over eating (16). There is a paucity of studies exploring disordered eating behaviours in women with PCOS; small studies have indicated a higher prevalence of PCOS in patients with eating disorders $(17,18)$. There are also reports suggesting both that disordered eating and bulimia nervosa are more common among women with PCOS (1921), though others have reported no difference (22). Furthermore, a meta-analysis showed an increased prevalence of depression and anxiety associated with PCOS compared with controls $(23,24)$, and it is known that negative emotions are a key predictor of binge eating $(25,26)$. Binge eating is positively associated with hyperandrogenism (27) and amenorrhea (28), with hyperandrogenism implicated within the pathogenesis of anovulation and menstrual irregularities $(29,30)$. The role of circulating testosterone concentrations in the aetiology of eating disorders has yet to be fully elucidated (31). Elevated testosterone concentrations may promote bulimic behaviours by influencing food cravings and impulse control $(31,32)$. A suggestion supported by the observation that anti androgenic treatment reduces bulimic behaviour (33). An alternative hypothesis is that recurrent binge eating may increase insulin levels, which, via decreased concentrations of sex hormone binding globulin, increase free circulating testosterone(34), ultimately negatively impacting upon follicular maturation and ovulation (28). 
Food cravings and obesity are positively correlated $(35,36)$ with evidence that individuals who are obese have higher frequencies of food cravings than healthy weight individuals (37). Food cravings may also discriminate between successful and unsuccessful dieters $(38,39)$. Recently, it has been reported that food craving was identified as a significant partial mediator in the relationships between elevated BMI and binge eating episodes (40). A food craving has been defined as an intense desire directed at a specific food or drink that is hard to resist (41). Craved and binged foods usually have a high energy density and fat content $(42,43)$ and previous studies have reported strong associations between cravings and intake of high-fat foods, sweets, and fast-food $(44,45)$. Food cravings are often anecdotally reported by women with PCOS (46); and a pilot study indicated women with PCOS had significantly higher Food Cravings-Trait scores compared with healthy women (47).

Raised androgens and menstrual disturbances have been associated with greater food cravings in women without PCOS (48). The underlying mechanism for the relationship is unclear; although circulating testosterone has been shown to stimulate appetite (49) and is associated with impaired impulse control, irritability and depression $(32,50)$. Accordingly, it has been proposed that elevated levels of androgens may promote food cravings (51).

There is an inadequate understanding of eating behaviours in women with PCOS. If binge eating and food cravings are common in this group, this needs to be highlighted to help clinicians focus on appropriate interventions and strategies to promote weight loss. Weight loss has already been identified as a key treatment for reproductive and metabolic outcomes for women with PCOS, but one which women report difficulty achieving. This study aims to report the prevalence of binge eating and food cravings and their relation to obesity risk in women with PCOS. It is hypothesised that a high proportion of binge eating and food craving behaviours will be identified.

\section{Methods}

\subsection{Participants}

The study recruited 583 women with PCOS and 95 women without PCOS (Figure 1). Healthy lean women were matched for weight, age and ethnicity to lean women with PCOS. Recruitment of study participants utilised social media sites and email advertisements at the University of Surrey. Participant eligibility was determined by a screening questionnaire. All women were at least 18 years of age. Participants were excluded if they were pregnant or breastfeeding. For women with PCOS, a diagnosis of PCOS by a healthcare professional was required. All overweight and obese women with PCOS were invited to participate in the 'Dieting experience' survey. Ethical approval was granted by the procedures of the 


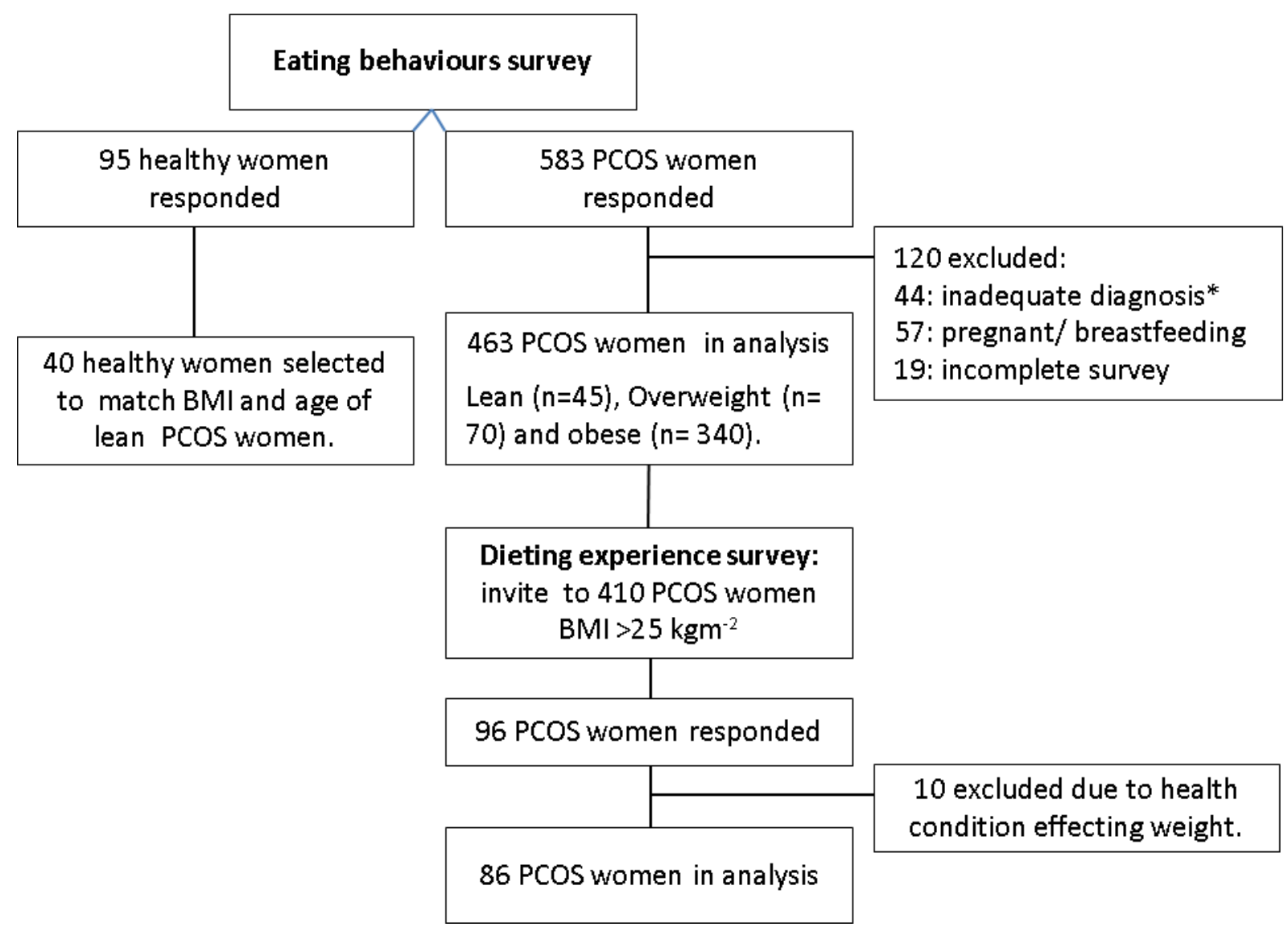

127 Figure 1. Recruitment of participants

128 * Inadequate diagnosis was a diagnosis by someone other than a healthcare professional. Data for the Dieting experience survey was collected anonymously.

\subsection{Assessments and measurements}

The online survey was presented on the Bristol Online Survey and SurveyMonkey ${ }^{\circledR}$ platforms. Informed consent procedures were embedded into the survey. Participants were asked questions relating to PCOS diagnosis, other medical conditions, self-reported PCOS symptoms, weight, height and dieting history similar to a previous study (52). Amenorrhea was considered present if participants provided a negative response to "have you had a period in the previous 12 months?"

The following validated questionnaires were used:

140 i) The Bulimia Investigatory Test, Edinburgh, (BITE) (53); recognised for its validity and reliability (54), is a 33-item self-report measure designed to identify individuals with symptoms of bulimia or binge eating. It consists of a symptom scale and a severity scale, 
which provides an index of the severity of binging and purging behaviour as defined by their frequency.

ii) The Food Cravings Questionnaire-Trait (FCQ-T), a 39-item self-report questionnaire whereby participants indicate how frequently each statement 'would be true for you in general' using a 6-point scale [range: 1 ('never or not applicable') to 6 ('always')]. Nine trait craving domains (Table 2) have been reported in healthy participants (55), those with eating disorders (56) and obese populations (57).

iii) The Three Factor Eating Questionnaire- Revised 18 (TFEQ-R18 version 2)(58), was selected to establish cognitive restraint, uncontrolled and emotional eating in the participants. It consisted of 18 statements, which participants indicate there agreement on a Likert like scale. The results are calculated into scores from 1 to 4 , with higher values indicating more of the behaviour.

The dieting experience survey for overweight and obese women with PCOS included items assessing dieting circumstances and perception of dieting strategies through an online questionnaire previously published by $(59,60)$.

\subsection{Data analysis}

Frequencies and descriptive statistics were generated using IBM® Statistical Package for the Social Sciences ${ }^{\circledR}$ (SPSS $\AA$ ) version 21. Data are presented as means \pm SD or number and percent. Normality of data was assessed; independent $t$ tests were used to compare variables between healthy women and women with PCOS; Mann-Whitney was used for nonparametric data. Cohen's d values and eta squared were calculated to establish size of effect. One-way or two-way ANOVA with Bonferroni post-hoc correction was chosen to compare variables between weight categories for women with PCOS. Partial correlations were used to control for body mass index (BMI). Multiple regression analysis with predictor values entered simultaneously was used to explore variance of binge eating behaviours, as measured by BITE symptom score; independent variables were total food cravings trait score, BMI, uncontrolled eating and emotional eating scores from TFEQ-R18.

\section{Results}

\subsection{Population characteristics}

The majority of women with PCOS were obese (73.4\%; $n=340), 15.1 \%(n=70)$ were overweight and $9.7 \%(n=45)$ were lean. Women with PCOS had a mean \pm SD weight of $98.6 \pm 27.4 \mathrm{~kg}(\mathrm{n}=460)$ and BMl of $36.0 \pm 9.1 \mathrm{kgm}^{-2}(\mathrm{n}=458)$. The majority of participants were Caucasian (84.7\%), with 3.9\% mixed race, 2.6\% Black, 2.2\% Asian and 6.7\% classified as 'other'. Responses were from North America $(n=303)$, Europe $(n=107)$, Australasia $(n=36)$ and other continents $(n=17)$. 
181 Diagnosis of PCOS was by a hospital or specialist doctor (60\%), general practitioner (38\%) or nurse (2\%). Prevalence of PCOS symptoms included hirsutism $85 \%(n=392)$; acne $56 \%$ $(n=257)$ and irregular menstruation $55 \%(n=255)$. Thirty one women reported a diagnosis of type 2 diabetes, 32 reported having depression and 11 reported a diagnosis of an eating disorder (table 1).

Table 1. Age, BMI and self-reported symptoms of women with PCOS

\begin{tabular}{|c|c|c|c|}
\hline & $\begin{array}{l}\text { Lean } \\
n=45\end{array}$ & $\begin{array}{c}\text { Overweight } \\
n=70\end{array}$ & $\begin{array}{l}\text { Obese } \\
n=340\end{array}$ \\
\hline Age (years) & $31.3(5.6)$ & $31.4(7.6)$ & $32.63(7.3)$ \\
\hline BMI (kgm-2) & $22.5(1.8)$ & $27.3(1.4)$ & $39.7(7.3)$ \\
\hline \multicolumn{4}{|l|}{ Response to the question: Do you have... } \\
\hline Hirsutism & $71 \%$ & $81 \%$ & $87 \% \%^{a}$ \\
\hline Acne & $62 \%$ & $46 \%$ & $57 \%$ \\
\hline Irregular menses & $51 \%$ & $53 \%$ & $56 \%$ \\
\hline Amenorrhea & $2 \%$ & $9 \%$ & $14 \%^{a}$ \\
\hline \multicolumn{4}{|c|}{ Positive response to the question: Do you have any other medical conditions? } \\
\hline Type 2 diabetes & $2 \%$ & $6 \%$ & $8 \%$ \\
\hline Depression & $11 \%$ & $14 \%$ & $5 \%{ }^{a}$ \\
\hline An eating disorder & $2 \%$ & $1 \%$ & $2 \%$ \\
\hline \multicolumn{4}{|l|}{ Weight management } \\
\hline Dieting to lose weight & $27 \%$ & $40 \%$ & $47 \%^{a}$ \\
\hline Agree with the statement 'I am a yo-yo dieter' & $35 \%$ & $33 \%$ & $57 \%$ \\
\hline
\end{tabular}

No significant difference between BMI groups in age $\left(p=0.23\right.$, One way ANOVA). ${ }^{a}$ Significant difference between BMI groups in prevalence hirsutism $\left(\chi^{2} p=0.012\right.$; Cramer $\left.V=0.14\right)$, amenorrhea $\left(\chi^{2}\right.$ $p=0.044$; Cramer $V=0.12)$, depression $\left(\chi^{2} p=0.012\right.$; Cramer $\left.V=0.14\right)$ and dieting to lose weight $\left(\chi^{2}\right.$ $\mathrm{p}<0.001$; Cramer $\mathrm{V}=0.24$ ).

\subsection{Food cravings in women with PCOS}

Nearly all of the women with PCOS self-reported craving foods (99\%); these included savoury and sweet, energy dense, high carbohydrate and high fat foods. BMI groups differed in FCQ-T scores (one-way ANOVA group effect, $F(2,452)=10.0 p<0.001$ ); multiple comparisons between groups (Bonferroni-adjusted) confirmed that obese women had significantly higher trait food craving scores than either lean $(p=0.001)$ or overweight $(p=0.01)$ women with PCOS (Table 2); specifically greater scores on the sub scales: 'Having intentions and plans to consume food', 'Lack of control over eating', 'Emotions that may be experienced before or during food cravings or eating' and 'Guilt from cravings/for giving into cravings' compared with lean women with PCOS (all $p<0.01$ ) (table 2). Total food cravings and $B M I$ were weakly correlated $(r=0.21 ; p<0.01)$.

Higher FCQ-T scores were observed in women with PCOS with acne $(n=257)$ compared to those without acne $(n=206)(130 \pm 3$ versus $124 \pm 3 ; p=0.02$, Cohen's $d=0.22)$. Hirsutism in women with PCOS did not significantly affect their reported food cravings whether assessed by BMI sub-group or with all weight categories combined (hirsute PCOS: $n=392$, FCQ-T 
score 127 \pm 30 ; non-hirsute PCOS: $n=71, F C Q-T=127 \pm 32 ; p=0.8$ ). Similarly neither depression nor irregular menses were found to significantly impact on FCQ-T within the PCOS cohort. When FCQ-T scores were compared between sub-groups of PCOS women with and without specific symptoms, only amenorrhea $(n=55)$ was associated with greater food cravings ( $139 \pm 32$ versus $126.2 \pm 30$ for all other women; $p=0.03$, Cohen's $d=0.42$ ). Obese women with PCOS who reported being on a diet to lose weight had similar FCQ-T scores compared with obese women with PCOS not dieting $(132 \pm 27 n=159$; versus $133 \pm 31$ $n=132, p=0.77$ ). However, one subscale did differ by dieting status, i.e. those on a diet to lose weight had a higher score for 'Guilt from cravings and/or for giving into them' compared to those not dieting (12.1 \pm 2.4 versus $11.5 \pm 3.0$ respectively; $p=0.049$, Cohen's $d=0.22)$.

Table 2. Food craving scores* for women with PCOS (mean (SD)).

\begin{tabular}{lccc}
\hline & $\begin{array}{c}\text { Lean } \\
\mathbf{n}=\mathbf{4 5}\end{array}$ & $\begin{array}{c}\text { Overweight } \\
\mathbf{n = 7 0}\end{array}$ & $\begin{array}{c}\text { Obese } \\
\mathbf{n}=\mathbf{3 4 0}\end{array}$ \\
\hline $\begin{array}{l}\text { Total food cravings score (FCQ-T) } \\
\begin{array}{l}\text { Subscales: } \\
\text { Having intentions and plans to consume food }\end{array}\end{array}$ & $\mathbf{1 1 4 . 0 ( 3 4 . 9 )}$ & $\mathbf{1 2 0 . 1 ( 2 9 . 5 )}$ & $\mathbf{1 3 1 . 6 ( 2 8 . 9 ) ^ { \mathrm { ac } }}$ \\
$\begin{array}{l}\text { Anticipation of positive reinforcement that may } \\
\text { result from eating }\end{array}$ & $14.1(3.2)$ & $9.8(2.8)$ & $10.9(2.6)^{\mathrm{ac}}$ \\
$\begin{array}{l}\text { Anticipation of relief from negative states and } \\
\text { feelings as a result of eating }\end{array}$ & $14.2(4.2)$ & $15.7(4.4)^{\mathrm{d}}$ \\
$\begin{array}{l}\text { Lack of control over eating } \\
\text { Thoughts or preoccupation with food }\end{array}$ & $16.3(7.4)$ & $7.9(3.1)$ & $8.9(2.9)^{\mathrm{d}}$ \\
$\begin{array}{l}\text { Craving as a physiological state } \\
\text { Emotions that may be experienced before or }\end{array}$ & $18.1(7.8)$ & $18.4(6.1)$ & $20.4(5.6)^{\mathrm{ad}}$ \\
$\begin{array}{l}\text { during food cravings or eating } \\
\text { Cues that may trigger food cravings }\end{array}$ & $11.9(5.1)$ & $13.3(7.3)$ & $20.8(7.0)^{\mathrm{b}}$ \\
Guilt from cravings and/or for giving into them & $13.1(4.3)$ & $13.6(4.5)$ & $14.1(3.1)$ \\
\hline
\end{tabular}

${ }^{a} \mathrm{p}<0.01,{ }^{b} \mathrm{p}<0.05$ : significantly different between lean and obese women with PCOS;

${ }^{c} p<0.01,{ }^{d}<<0.05$ : significantly different between overweight and obese women with PCOS; one-way ANOVA with Bonferroni post-hoc adjustment.

*Possible ranges for the scale scores: Total score, 39-234; Having intentions and plans to consume food, 3-18; Anticipation of positive reinforcement that may result from eating, 5-30; Anticipation of relief from negative states and feelings as a result of eating, 3-18; Lack of control over eating, 6-36; Thoughts or preoccupation with food,7-42; Craving as a physiological state, 4-24; Emotions that may be experienced before or during food cravings or eating, 4-24; Cues that may trigger food cravings, 424; Guilt from cravings and/or for giving into them, 3-18.

\subsection{Binge eating behaviours in women with PCOS}

Only $20 \%$ of obese women with PCOS were free of both compulsive eating and binge-eating (Figure 2). Sixty percent of obese women with PCOS ( $n=200)$ presented scores that indicated binge eating behaviour; 39\% presented with clinically significant or high degree of severity $(n=130)$ (table 3 ), but only $2 \%$ of obese women with PCOS reported a diagnosed eating disorder (table1). A significantly greater proportion of obese women with PCOS exhibited binge eating behaviours compared with overweight and lean women with PCOS (Figure 2). 


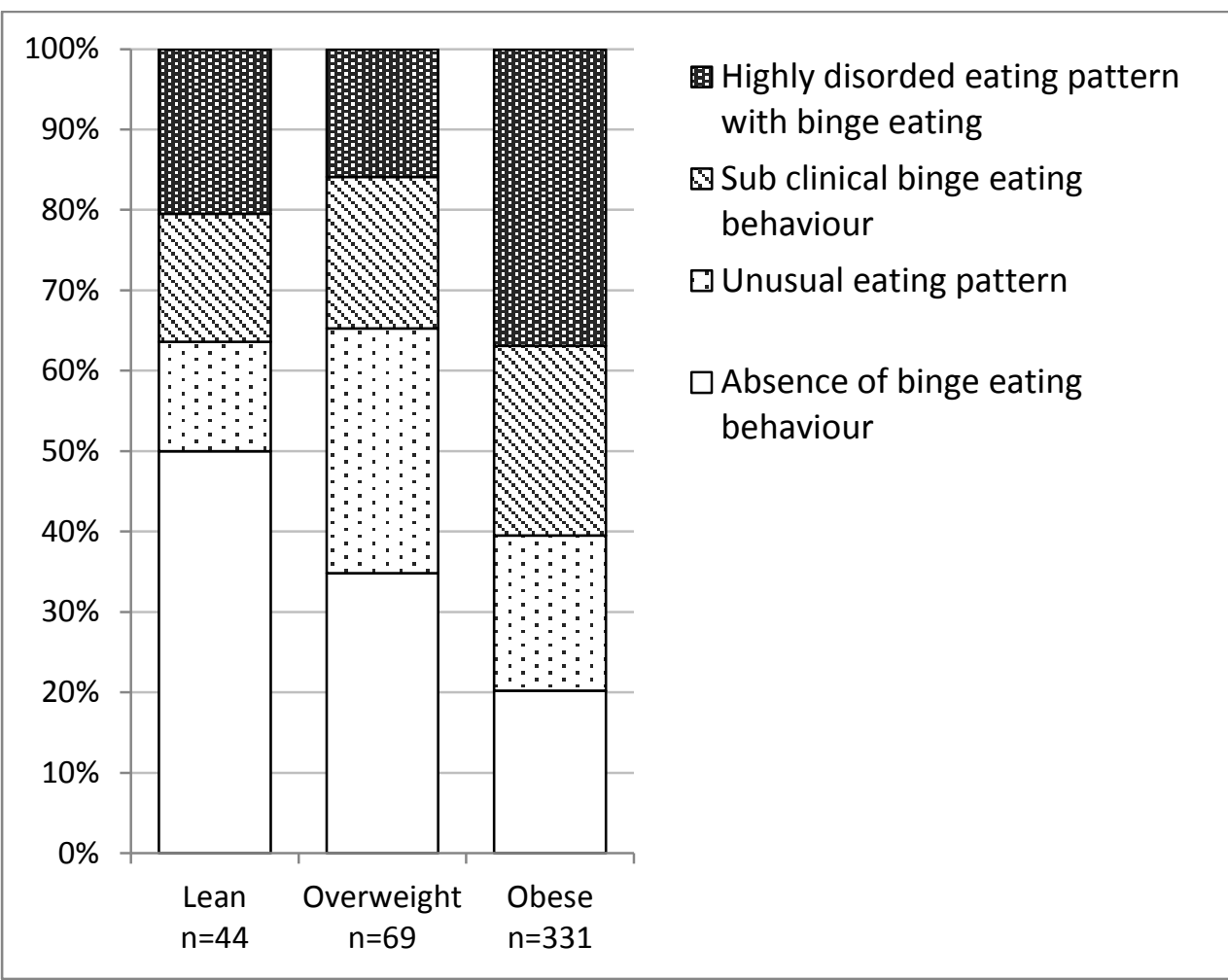

241 Figure 2. Proportion of women with PCOS exhibiting binge eating behaviour.

242 Significant difference in proportion of binge eating symptoms between BMI groups $\left(\chi^{2} p<0.001\right.$,

243 Cramer's V =0.25).

245 Similar to the results for reported food-cravings, sub-groups created according to the

246 presence or absence of specific symptoms (hirsutism, depression or irregular menses) did

247 not show different binge eating symptom scores. However once again, women who reported

248 acne $(n=257)$ had higher binge eating symptom scores ( $16.0 \pm 7$ versus $13.6 \pm 7 ; p=0.01$,

249 Cohen's $d=0.32)$ than those without $(n=206)$, likewise those who reported amenorrhea

$250(n=55)$ when compared with women who reported having menses in the previous 12 months $251(n=408 ; 17.0 \pm 7.0$ versus $14.7 \pm 7.1 ; p=0.02$, Cohen's $d=0.33)$. Obese women with PCOS

252 who reported being on a diet to lose weight had similar binge eating symptom scores

253 compared with obese women with PCOS not dieting (16.5 $\pm 6.3, n=159$; versus 16.0 \pm 7.1 ,

$254 \mathrm{n}=132, \mathrm{p}=0.36)$.

Table 3. Binge eating scores from women with PCOS.

\begin{tabular}{lccc}
\hline & $\begin{array}{c}\text { Lean } \\
\mathbf{n}=\mathbf{4 4}\end{array}$ & $\begin{array}{c}\text { Overweight } \\
\mathbf{n}=69\end{array}$ & $\begin{array}{c}\text { Obese } \\
\mathbf{n}=331\end{array}$ \\
\hline Binge eating symptom score*; Mean (SD) & $\mathbf{1 0 . 9 ( 7 . 8 )}$ & $\mathbf{1 2 . 4}(\mathbf{6 . 8 )}$ & $\mathbf{1 5 . 9}(\mathbf{6 . 8})^{\text {ab }}$ \\
\hline Subscales: & & & \\
\hline $\begin{array}{l}\text { Absence of both compulsive eating and binge- } \\
\text { eating. }\end{array}$ & $50 \% \mathrm{n}=22$ & $34.8 \% \mathrm{n}=24$ & $20.2 \% \mathrm{n}=67$ \\
\hline Unusual eating pattern might be a compulsive & $13.6 \% \mathrm{n}=6$ & $30.4 \% \mathrm{n}=21$ & $19.3 \% \mathrm{n}=64$ \\
\hline
\end{tabular}


eater who eats excessively but does not binge-eat.

Subclinical group of binge-eaters, either in the initial stages of the disorder or recovered bulimics.

Highly disordered eating pattern and the presence of binge-eating.

$5.9 \% n=7 \quad 18.8 \% n=13 \quad 23.6 \% n=78$

$20.5 \% n=9 \quad 15.9 \% n=11 \quad 36.9 \% n=122$

\begin{tabular}{llll}
\hline Binge eating severity score $^{*}$; Mean (SD) & $\mathbf{2 . 8} \mathbf{( 2 . 1 )}$ & $\mathbf{3 . 6} \mathbf{( 3 . 3 )}$ & $\mathbf{4 . 3} \mathbf{( 3 . 2 )}^{\mathbf{a}}$ \\
\hline Normal & $86.4 \% \mathrm{n}=38$ & $76.8 \% \mathrm{n}=53$ & $60.7 \% \mathrm{n}=201$ \\
\hline Clinically significant behaviour & $13.6 \% \mathrm{n}=6$ & $14.5 \% \mathrm{n}=10$ & $32.3 \% \mathrm{n}=107$ \\
\hline High degree of severity & $0 \% \quad \mathrm{n}=0$ & $8.7 \% \mathrm{n}=6$ & $6.9 \% \quad \mathrm{n}=23$ \\
\hline
\end{tabular}

$\mathrm{p}<0.01$ : significantly different between lean and obese women with PCOS;

${ }^{b} \mathrm{p}<0.01$ : significantly different between overweight and obese women with PCOS; analysis by oneway ANOVA with Bonferroni post-hoc adjustment. " Possible range for binge eating symptom score, 0 30 ; binge eating severity score, 2-39.

261

262

263

264

265

266

267

268

269

270

271

272

273

274

275

276

277

278

279

280

281

282

283

284

285

286

287

\subsection{Emotional eating, cognitive restraint and uncontrolled eating scores in women} with PCOS

Emotional eating scores were higher in obese compared with lean women with PCOS (obese 2.7 \pm 0.8 , overweight $2.5 \pm 0.8$ and lean $2.3 \pm 0.9 ; p=0.006$, eta squared $=0.021$, post hoc obese versus lean $p=0.013$; score ranges from 1-4). Emotional eating scores were positively associated with total food craving score $(r=0.74 ; p<0.001)$ and binge eating symptom score $(r=0.64, p<0.001)$. These strong correlations remained when controlled for BMI. Conversely, cognitive restraint scores were lower in obese compared with lean women with PCOS (obese 2.5 \pm 0.7 , overweight $2.7 \pm 0.8$ and lean $2.8 \pm 0.8 ; p=0.001$, eta squared $=0.027$, post hoc obese versus lean $p=0.004$ ). Weak negative associations were observed between cognitive restraint scores and total food craving score $(r=-0.23, p<0.001)$ and binge eating symptom score $(r=-0.15, p=0.01)$, although when controlled for the influence of $B M I$ only the weak correlation with food cravings remained $(r=-0.2, p<0.001)$. There was a trend towards greater uncontrolled eating scores in obese women with PCOS (obese 2.6 \pm 0.4 , overweight; $2.5 \pm 0.4$ and lean $2.5 \pm 0.5 ; p=0.053$ ). Uncontrolled eating scores were positively associated with total food craving score $(r=0.67 ; p<0.001)$ and binge eating symptom score $(r=0.56, p<0.001)$. These strong correlations remained when controlled for BMI.

\subsection{Association between binge eating and food cravings in women with PCOS}

Binge eating symptom score and food cravings total scores were strongly correlated $(r=0.745 ; p<0.001, n=463$ women with PCOS. Multiple regression analysis to predict contribution to binge eating symptom score included BMI, total food cravings score, uncontrolled, emotional and cognitive restraint eating scores as predictor variables. The model explained $57 \%$ of the variance in binge eating symptom scores $(F(d f 1, d f 2)=130.4$; $p<0.001$ ): food cravings total score (beta $=0.53 ; p<0.001$ ), emotional eating score (beta $=0.18 ; p<0.001)$, BMI (beta $=0.11 ; p<0.001)$ and uncontrolled eating score $($ beta $=0.09$ 
$\mathrm{p}=0.02$ ) independently contributed to this explained variance, whereas cognitive restraint was not an independent predictor (beta 0.03; $p=0.28$ ).

\subsection{Comparisons between lean healthy women and lean women with PCOS}

292

Lean healthy women $(n=40)$ and lean women with PCOS $(n=45)$ were similar in ethnicity

293 (both $>95 \%$ Caucasian), age (28.3 \pm 8.5 years and $31.3 \pm 5.6$ years; $p=0.07)$ and $B M I$

294 $\left(21.8 \pm 1.6 \mathrm{kgm}^{-2}\right.$ and $\left.22.5 \pm 1.8 \mathrm{kgm}^{-2} ; \mathrm{p}=0.09\right)$. They returned similar total food craving scores, although, women with PCOS reported significantly higher scores on the food craving subscale 'Anticipation of Positive Reinforcement That May Result From Eating' ( $p=0.017$, Cohen's $d=0.52$ ) and 'Anticipation of Relief From Negative States and Feelings as a Result of Eating' ( $\mathrm{p}=0.009$, Cohen's $d=0.56$ ) compared with lean healthy women (table 4 ). Significantly higher mean binge eating score was observed in lean women with PCOS compared with lean healthy women $(10.9 \pm 7.8$ versus $7.4 \pm 6.0, p=0.024$; Cohen's $d=0.50$ (table 4). Lean women with PCOS had a significantly higher proportion of subclinical/ highly disordered eating $(36 \%, n=16)$ compared with lean healthy women $\left(12 \%, n=5 ; \chi^{2} p=0.02\right.$ phi $=0.28$ ). Multiple regression analysis to predict contribution to binge eating symptom score included PCOS diagnosis, BMI, uncontrolled eating score, emotional eating score and total food cravings score as predictor variables. The model explained $68 \%$ of the variance in binge eating symptom scores $(F(d f 1, d f 2)=31.2 ; p<0.001)$; food cravings total score (beta $=0.72 ; p<0.001$ ), PCOS status (beta $0.14 ; p=0.042$ ), independently contributed to this explained variance, however emotional eating score (beta $=0.07 ; p=0.9$ ), uncontrolled eating score (beta $=0.107 ; p=0.23$ ) and BMI (beta $=0.008 ; p=0.91$ ) did not.

Table 4. Food craving and binge eating scores from lean healthy women and lean women with PCOS.

\begin{tabular}{lcc}
\hline & $\begin{array}{c}\text { Healthy } \\
\mathbf{n = 4 0}\end{array}$ & $\begin{array}{c}\mathbf{P C O S} \\
\mathbf{n = 4 5}\end{array}$ \\
\hline Total food cravings score*; Mean (SD) & $\mathbf{1 0 5 . 6 ( 2 6 . 6 )}$ & $\mathbf{1 1 4 . 0 ( 3 4 . 9 )}$ \\
\hline Subscales: & & \\
\hline Having intentions and plans to consume food & $8.6(2.4)$ & $9.1(3.2)$ \\
\hline Anticipation of positive reinforcement that may result from eating & $12.6(3.8)^{\mathrm{a}}$ & $14.7(4.3)^{\mathrm{a}}$ \\
\hline $\begin{array}{l}\text { Anticipation of relief from negative states and feelings as a result } \\
\text { of eating }\end{array}$ & $6.4(2.2)^{\mathrm{a}}$ & $8.0(3.4)^{\mathrm{a}}$ \\
\hline Lack of control over eating & $14.5(5.4)$ & $16.3(7.2)$ \\
\hline Thoughts or preoccupation with food & $17.3(6.2)$ & $18.1(7.8)$ \\
\hline Craving as a physiological state & $12.3(3.1)$ & $13.1(3.0)$ \\
\hline $\begin{array}{l}\text { Emotions that may be experienced before or during food } \\
\text { cravings or eating }\end{array}$ & $11.2(4.2)$ & $11.9(5.1)$ \\
\hline Cues that may trigger food cravings & $14.0(4.2)$ & $13.1(4.3)$ \\
\hline Guilt from cravings and/or for giving into them & $8.8(3.6)$ & $9.6(3.7)$ \\
\hline Binge eating symptom score $*$ Mean (SD) & $\mathbf{7 . 4 ( 6 . 0 )}$ & $\mathbf{1 0 . 9 ( 7 . 8 )}$ \\
\hline
\end{tabular}




\begin{tabular}{llc}
\hline Absence of both compulsive eating and binge-eating. & $65 \% \mathrm{n}=26$ & $50 \% \mathrm{n}=22$ \\
\hline $\begin{array}{l}\text { Unusual eating pattern might be a compulsive eater who eats } \\
\text { excessively but does not binge-eat. }\end{array}$ & $17.5 \% \mathrm{n}=7$ & $13.6 \% \mathrm{n}=6$ \\
\hline $\begin{array}{l}\text { Subclinical group of binge-eaters, either in the initial stages of } \\
\text { the disorder or recovered bulimics. }\end{array}$ & $5.0 \% \mathrm{n}=2$ & $15.9 \% \mathrm{n}=7$ \\
\hline $\begin{array}{l}\text { Highly disordered eating pattern and the presence of binge- } \\
\text { eating }\end{array}$ & $7.5 \% \mathrm{n}=3$ & $20.5 \% \mathrm{n}=9$ \\
\hline Binge eating severity score*; Mean (SD) & $\mathbf{2 . 0}(\mathbf{2 . 2})$ & $\mathbf{2 . 8} \mathbf{( 2 . 1 )}$ \\
\hline Normal & $89.5 \% \mathrm{n}=34$ & $86.4 \% \mathrm{n}=38$ \\
\hline Clinically significant behaviour & $7.9 \% \mathrm{n}=3$ & $13.6 \% \mathrm{n}=6$ \\
\hline High degree of severity & $2.6 \% \mathrm{n}=1$ & $0 \% \quad \mathrm{n}=0$ \\
\hline
\end{tabular}

${ }^{a} p<0.01$ : Significant difference between healthy and PCOS women; independent $t$ test.

*See Tables 2 and 3 for notes on possible scale score ranges.

\subsection{Dieting experience in women with PCOS}

The eating behaviours study indicated a high proportion of overweight and obese women with PCOS expressed an interest in losing weight (96\% and $99 \%$ respectively). Despite these intentions only $47 \%$ of obese women with PCOS reported to be modifying their diet to promote weight loss and a further $11 \%$ were modifying their diet to avoid weight gain $(40 \%$ and $11 \%$ comparatively for overweight women with PCOS). This was explored further in the Dieting Experience Survey completed by 86 overweight or obese women with PCOS; mean BMI $37.4 \pm 7.1 \mathrm{kgm}^{-2}$ (6 participants had incomplete data for their BMI). Most of the respondents were of Caucasian ethnicity $86 \%(n=74)$. Nearly all $(93 \%)$ of the women reported to have been on diets previously to lose weight, though only $13 \%$ reported stopping the diet as they had attained their goal of weight loss or duration. Hunger and frustration were the most common reason for abandoning a dietary change (57\%) followed by perceived ineffectiveness of the diet (40\%) and expense (35\%). Barriers reported to 'often' or 'routinely' impact on achieving their goal of staying healthy were; 'too tired' (71\%), 'interferes with other responsibilities' (57\%), 'lack of time' (55\%), 'embarrassment about my appearance' (46\%), 'feeling what I do does not help' (46\%), 'lack of money' (40\%), and 'lack of help from healthcare professionals' (24\%).

\section{Discussion}

\subsection{Binge eating behaviour}

The current study has reported binge eating behaviour in the majority of obese women with PCOS, and more than a third of overweight and healthy weight women with PCOS. This is the first time binge eating has been reported with a validated tool in a large cohort of women with PCOS. Regression analysis demonstrated the interrelationship between binge eating 
behaviours and food cravings in the women with PCOS, similar to previous studies in obese and overweight non PCOS participants $(61,62)$.

Direct comparisons with published studies of non PCOS populations need to take into account different methods for assessing binge eating behaviour. The prevalence of clinically significant binge eating behaviour in our cohort of obese women with PCOS (39\%) is greater than reports in non PCOS obese women within a large Italian study whereby $24-32 \%$ of obese women were classified as exhibiting binge eating behaviour as defined by a score $\geq 18$ on the Binge Eating scale (63), similarly, in the United States, $27 \%$ of overweight/obese women had some bingeing or probable binge eating disorder (64). Larrson et al. (2015) also recently reported women with PCOS $(n=72)$ had a higher Eating Attitudes Test score, reflecting disordered eating, compared with controls $(n=30)$, though women with PCOS had a significantly higher BMI (19). Our cohort of lean women with PCOS had significantly higher binge eating symptom scores compared with lean healthy women in agreement with the findings of Hart et al. (2012)(47).

Women with PCOS who reported amenorrhea had significantly higher binge eating symptom scores compared with those with menses, this agrees with the association between binge eating and menstrual dysfunction in women without PCOS observed by Algars et al. (2014)(28). The pathogenesis is believed to involve elevated testosterone (31), we did observe higher binge eating symptom scores in PCOS women with acne compared to those without acne, however, scores were similar in hirsute and non-hirsute women with PCOS, although it should be noted that the study was not powered to detect differences between symptom sub-groups and so these results should be viewed with caution. We suggest future studies explore menstrual dysfunction and hyperandrogenism in relation to eating behaviours in women with PCOS including investigation of hormonal influencers in binge eating (65) which was beyond the scope of this study.

Binge eating has a complex and incompletely understood aetiology. Contributing factors include anxiety, depression and negative body image (66-68), all frequently observed in women with PCOS $(23,24,69)$. Rodino et al. (2016) recently reported that infertile obese women, including a small cohort of obese women with PCOS experienced lower selfesteem, body shape concerns and binge eating behaviours (70). Our study was not powered to report a difference in binge eating symptoms and depression and there is a gap in the literature exploring this potential relationship in PCOS especially given the high prevalence of depression in women with PCOS (24). Further research into the causes and possible long term consequences of binge eating behaviours in lean women with PCOS is needed to investigate whether bingeing contributes to future weight gain in this syndrome. 


\subsection{Food craving}

Food cravings are often anecdotally reported by women with PCOS (46), though there is a paucity of research and the current study is the first to report food cravings in a large cohort of women with PCOS using a validated tool. Our cohort reported food craving questionnaireTrait (FCQ-T) scores in the obese women with PCOS $(131.6 \pm 28.9)$ that were higher than published values for non PCOS populations, e.g. 111.5 \pm 36.8 in an Italian cohort of 411 overweight and obese women, and 86 obese men (71) and 119.2 \pm 31.4 for 109 overweight and obese in the United States (57). Direct comparisons are limited by the fact that these studies include males and overweight participants; further studies are needed to compare food cravings in obese women with and without PCOS. Of interest, food craving scores for obese women with PCOS are more similar to the scores reported by Jarosz et al. (2007) in obese women with binge eating disorder or bulimia $(137.6 \pm 40.2 n=7)$ or night eating syndrome (122.5 $\pm 19.0 \mathrm{n}=16)$ (72) and normal-weight university students with food addiction (147.1 $\pm 34.5, n=48)(38)$, although some of those scores were based on very small numbers. The current study revealed lean women with PCOS and lean healthy women had similar total FCQ-T scores; however, women with PCOS did have greater 'anticipation of positive reinforcement that may result from eating' and 'anticipation of relief from negative states and feelings as a result of eating'. These both address feelings of satisfaction from eating and the clinical relevance of these aspects needs to be explored in more detail. Of note, although food cravings are strongly correlated to binge eating, which is highly prevalent in women with PCOS, the facets of food cravings that distinguished PCOS from healthy women are those concerning anticipation of reinforcement and relief from negative emotions and these may be crucial for the development of binge eating (73). Women with PCOS who reported amenorrhea had significantly higher FCQ-T scores compared with those with menses; this agrees with the association reported between menstrual dysfunction and fast food cravings in overweight/ obese women (48). However, like binge eating symptom scores, FCQ-T scores were higher in PCOS women with acne compared to those without acne, though scores were similar in hirsute and non-hirsute women with PCOS; whereas Lim et al. (2009) observed greater high fat food cravings in women with hyperandrogenism (48). This is an area for further study that requires more robust measurements of menstrual function and androgen excess in women with PCOS.

411 Another factor that may influence food cravings is dieting status, i.e. restricting energy intake 412 to lose weight: repeatedly eating palatable energy-rich food such as chocolate when hungry 413 has been shown to exacerbate craving in established chocolate cravers and induce craving 414 in previously non-cravers (43). Therefore, we examined whether trait craving or binge eating scores differed by dieting status in obese women with PCOS; by and large, there were no 
differences, with the exception that dieting women reported slightly more guilt at having cravings or giving in to them, presumably because such behaviour was contrary to their attempts to limit energy intake. In agreement with this, when controlled for BMI, there was no correlation between cognitive restraint eating and food craving scores.

\subsection{Weight management}

A large proportion of the overweight and obese women with PCOS were not following dietary modifications to prevent weight gain or promote weight loss, although the majority of women had tried to lose weight in the past. Similarly a high dropout rate has been reported in a meta-analysis of 10 lifestyle intervention program studies in infertile overweight or obese women (74). In our study only $13 \%$ of overweight and obese women with PCOS reported attaining their goal of weight or duration as their reason for stopping the diet emphasising the difficulty associated with weight loss and weight maintenance in this population. Barriers to successful weight loss included feeling frustrated and hungry, interference with other responsibilities, adherence difficulty, lack of time and tiredness, are in line with people wanting to lose weight $(59,75)$. The hunger reported by women could allude to the lower meal stimulated grehlin levels measured in women with PCOS (76), additionally studies have shown than testosterone stimulates food intake (49). Given that weight management is the primary treatment for women with PCOS understanding the barriers and reasons for non-compliance is crucial.

\subsection{Clinical Implications}

Binge eating behaviours may be a contributor to the difficulties associated with weight management reported amongst women with PCOS. It is important that the high prevalence of binge eating behaviours in women with PCOS is included within clinical guidelines, with suggested screening for disordered eating to help towards appropriate strategies to help women with binge eating behaviours (77). In particular in lean women with PCOS, often overlooked in the clinical and research setting, strategies to help with binge eating behaviours could be an effective intervention to prevent future weight gain. To strengthen the evidence it is important that the high prevalence of binge eating behaviours in obese women with PCOS reported in this study is explored in a large case control study. The prevalence of food cravings in PCOS is less clear. Cognitive behavioural therapy (78) and mindfulness (79) within interventions to help individuals reduce their food cravings has been successful, though further study in this area is needed before clinical interventions are recommended (36). In addition to the limitations of the present study highlighted above, the self-report nature of the PCOS diagnosis should be noted, with limited information on hyperandrogenism and menstrual function collected. Information on menstrual cycle was not 
453 collected, which would have been valuable given the variations in food cravings through the

454 menstrual cycle shown previously (80); however this should not have affected between

455 group comparisons.

456

457

\subsection{Conclusion}

458 This study is the largest, to date, to robustly report binge eating and food cravings in women

459 with PCOS, contributing significantly to the existing anecdotal evidence and small scale

460 studies. Such disordered eating behaviours may be a contributor to and/ or a function of the

461 difficulties with weight management reported amongst women with PCOS. Clinician

462 awareness of binge eating in individual women with PCOS should influence the choice of

463 weight management approaches: thus screening of overweight and obese women with

464 PCOS for binge eating is recommended. To further our understanding of disordered eating

465 behaviours in women with PCOS we suggest, BMI matched case-control, studies to assess

466 the influence of medication, hormonal and psychological contributors to binge eating

467 behaviours in women with PCOS.

468

469 Acknowledgments:

470 Thanks to R Evill and A Calvert for their help with data collection. The studies were funded 471 by the University of Roehampton and University of Surrey. 
1. March WA, Moore VM, Willson KJ, Phillips DI, Norman RJ, Davies MJ. The prevalence of polycystic ovary syndrome in a community sample assessed under contrasting diagnostic criteria. Hum Reprod. 2010 Feb;25(2):544-51.

2. Moran LJ, Misso ML, Wild RA, Norman RJ. Impaired glucose tolerance, type 2 diabetes and metabolic syndrome in polycystic ovary syndrome: a systematic review and metaanalysis. Hum Reprod Update. 2010 Jul-Aug;16(4):347-63.

3. Lim SS, Davies MJ, Norman RJ, Moran LJ. Overweight, obesity and central obesity in women with polycystic ovary syndrome: a systematic review and meta-analysis. Hum Reprod Update. 2012 Nov-Dec;18(6):618-37.

4. Lim S, Norman R, Davies M, Moran L. The effect of obesity on polycystic ovary syndrome: a systematic review and meta-analysis. Obesity Reviews. 2013;14(2):95-109.

5. Haqq L, McFarlane J, Dieberg G, Smart N. The Effect of Lifestyle Intervention on Body Composition, Glycemic Control, and Cardiorespiratory Fitness in Polycystic Ovarian Syndrome: A Systematic Review and Meta-Analysis. Int J Sport Nutr Exerc Metab. 2015 Dec;25(6):533-40.

6. Haqq L, McFarlane J, Dieberg G, Smart N. Effect of lifestyle intervention on the reproductive endocrine profile in women with polycystic ovarian syndrome: a systematic review and meta-analysis. Endocr Connect. 2014 Feb 28;3(1):36-46.

7. PCOS Australian Alliance. Evidence-based guideline for the assessment and management of polycystic ovary syndrome. 2011.

8. National Institute for Health and Care Excellence. Polycystic Ovary Syndrome: Clinical Knowledge Summary. 2013.

9. Legro RS, Arslanian SA, Ehrmann DA, Hoeger KM, Murad MH, Pasquali R, et al. guideline. The Journal of Clinical Endocrinology \& Metabolism. 2013;98(12):4565-92.

10. Royal College of Obstetricians and Gynaecologists. Polycystic Ovary Syndrome, Longterm consequences (Green-top Guideline No. 33). 2014. Report No.: 33.

11. Conway G, Dewailly D, Diamanti-Kandarakis E, Escobar-Morreale HF, Franks S, Society of Endocrinology. Eur J Endocrinol. 2014 Oct;171(4):P1-29. predict weight gain in adolescents? Findings from project EAT-II: a 5-year longitudinal study. J Am Diet Assoc. 2007;107(3):448-55.

509 2007;15(11):2748-60. 
14. Elfhag K, Rössner S. Who succeeds in maintaining weight loss? A conceptual review of factors associated with weight loss maintenance and weight regain. Obesity reviews. $2005 ; 6(1): 67-85$.

15. Moroshko I, Brennan L, O'Brien P. Predictors of dropout in weight loss interventions: a systematic review of the literature. Obesity reviews. 2011;12(11):912-34.

16. American Psychiatric Association. Diagnostic and statistical manual of mental disorders (DSM-5®). American Psychiatric Pub; 2013.

17. Naessén S, Carlström K, Garoff L, Glant R, Hirschberg AL. Polycystic ovary syndrome in bulimic women-an evaluation based on the new diagnostic criteria. Gynecological endocrinology. 2006;22(7):388-94.

18. Morgan J, Scholtz S, Lacey H, Conway G. The prevalence of eating disorders in women with facial hirsutism: an epidemiological cohort study. Int J Eat Disord. 2008;41(5):427-31.

19. Larsson I, Hulthén L, Landén M, Pålsson E, Janson $P$, Stener-Victorin E. Dietary intake, resting energy expenditure, and eating behavior in women with and without polycystic ovary syndrome. Clinical Nutrition. 2015.

20. Hollinrake E, Abreu A, Maifeld M, Van Voorhis BJ, Dokras A. Increased risk of depressive disorders in women with polycystic ovary syndrome. Fertil Steril. 2007;87(6):1369-76.

21. McCluskey S, Evans C, Lacey JH, Pearce JM, Jacobs H. Polycystic ovary syndrome and bulimia. Fertil Steril. 1991 Feb;55(2):287-91.

22. Michelmore KF, Balen AH, Dunger DB. Polycystic ovaries and eating disorders: Are they related? Hum Reprod. 2001 Apr;16(4):765-9.

23. Dokras A, Clifton S, Futterweit W, Wild R. Increased prevalence of anxiety symptoms in women with polycystic ovary syndrome: systematic review and meta-analysis. Fertil Steril. 2012;97(1):225,230. e2.

24. Dokras A, Clifton S, Futterweit W, Wild R. Increased risk for abnormal depression scores in women with polycystic ovary syndrome: a systematic review and meta-analysis. Obstet Gynecol. 2011 Jan;117(1):145-52.

25. Mason TB, Heron KE, Braitman AL, Lewis RJ. A daily diary study of perceived social isolation, dietary restraint, and negative affect in binge eating. Appetite. 2016;97:94-100.

26. Goldfield GS, Adamo KB, Rutherford J, Legg C. Stress and the relative reinforcing value of food in female binge eaters. Physiol Behav. 2008;93(3):579-87.

27. Sundblad C, Bergman L, Eriksson E. High levels of free testosterone in women with bulimia nervosa. Acta Psychiatr Scand. 1994;90(5):397-8.

28. Ålgars M, Huang L, Von Holle AF, Peat CM, Thornton LM, Lichtenstein P, et al. Binge eating and menstrual dysfunction. J Psychosom Res. 2014;76(1):19-22.

29. Haning RV,Jr, Hackett RJ, Flood CA, Loughlin JS, Zhao QY, Longcope C. Testosterone, a follicular regulator: key to anovulation. J Clin Endocrinol Metab. 1993 Sep;77(3):710-5. 
30. Van Anders SM, Watson NV. Menstrual cycle irregularities are associated with testosterone levels in healthy premenopausal women. Am J Hum Biol. 2006 NovDec;18(6):841-4.

31. Baker JH, Girdler SS, Bulik CM. The role of reproductive hormones in the development and maintenance of eating disorders. Expert review of obstetrics \& gynecology. 2012;7(6):573-83.

32. Cassin SE, von Ranson KM. Personality and eating disorders: a decade in review. Clin Psychol Rev. 2005;25(7):895-916.

33. Naessen S, Carlström K, Byström B, Pierre Y, Hirschberg AL. Effects of an antiandrogenic oral contraceptive on appetite and eating behavior in bulimic women. Psychoneuroendocrinology. 2007;32(5):548-54.

34. Nestler JE. Insulin regulation of human ovarian androgens. Hum Reprod. 1997 Oct;12 Suppl 1:53-62.

35. Chao A, Grilo CM, White MA, Sinha R. Food cravings, food intake, and weight status in a community-based sample. Eating Behav. 2014;15(3):478-82.

36. Potenza MN, Grilo CM. How relevant is food craving to obesity and its treatment? Food cravings. 2015:89.

37. Franken $\mathrm{IH}$, Muris $\mathrm{P}$. Individual differences in reward sensitivity are related to food craving and relative body weight in healthy women. Appetite. 2005;45(2):198-201.

38. Meule A, Lutz A, Vögele C, Kübler A. Food cravings discriminate differentially between successful and unsuccessful dieters and non-dieters. Validation of the Food Cravings Questionnaires in German. Appetite. 2012;58(1):88-97.

39. Batra P, Das SK, Salinardi T, Robinson L, Saltzman E, Scott T, et al. Relationship of cravings with weight loss and hunger. Results from a 6month worksite weight loss intervention. Appetite. 2013;69:1-7.

40. Joyner MA, Gearhardt AN, White MA. Food craving as a mediator between addictive-like eating and problematic eating outcomes. Eating Behav. 2015;19:98-101.

41. White MA, Whisenhunt BL, Williamson DA, Greenway FL, Netemeyer RG. Development and validation of the food-craving inventory. Obes Res. 2002;10(2):107-14.

42. Gilhooly C, Das S, Golden J, McCrory M, Dallal G, Saltzman E, et al. Food cravings and energy regulation: the characteristics of craved foods and their relationship with eating behaviors and weight change during 6 months of dietary energy restriction. Int $\mathrm{J}$ Obes. 2007;31(12):1849-58.

43. Gibson EL, Desmond E. Chocolate craving and hunger state: implications for the acquisition and expression of appetite and food choice. Appetite. 1999;32(2):219-40.

44. Martin CK, O'Neil PM, Pawlow L. Changes in food cravings during low-calorie and verylow-calorie diets. Obesity. 2006;14(1):115-21. 
45. Forman EM, Hoffman KL, Juarascio AS, Butryn ML, Herbert JD. Comparison of acceptance-based and standard cognitive-based coping strategies for craving sweets in overweight and obese women. Eating Behav. 2013;14(1):64-8.

46. Herriot $A$, Whitcroft $S$, Jeanes $Y$. An retrospective audit of patients with polycystic ovary syndrome: the effects of a reduced glycaemic load diet. Journal of human nutrition and dietetics. 2008;21(4):337-45.

47. Hart K, Evil R, Clavert A, Hodgson J, Gibson EL, Jeanes Y. Eating behaviours in women with polycystic ovary syndrome and healthy comparators. Journal of human nutrition and dietetics. 2012;25(6):604.

48. Lim SS, Norman RJ, Clifton PM, Noakes M. Hyperandrogenemia, psychological distress, and food cravings in young women. Physiol Behav. 2009;98(3):276-80.

49. Asarian L, Geary N. Modulation of appetite by gonadal steroid hormones. Philos Trans R Soc Lond B Biol Sci. 2006 Jul 29;361(1471):1251-63.

50. Eriksson E, Sundblad C, Landen M, Steiner M. Behavioural effects of androgens in women. Mood disorders in women.London: Martin Dunitz. 2000:233-46.

51. Hirschberg AL. Sex hormones, appetite and eating behaviour in women. Maturitas. 2012;71(3):248-56.

52. Barr S, Hart K, Reeves S, Sharp K, Jeanes Y. Habitual dietary intake, eating pattern and physical activity of women with polycystic ovary syndrome. Eur J Clin Nutr.

$2011 ; 65(10): 1126-32$.

53. Henderson M, Freeman CP. A self-rating scale for bulimia. The 'BITE'. Br J Psychiatry. 1987 Jan;150:18-24.

54. Burton AL, Abbott MJ, Modini M, Touyz S. Psychometric evaluation of self-report measures of binge eating symptoms and related psychopathology: A systematic review of the literature. Int J Eat Disord. 2015.

55. Cepeda-Benito A, Gleaves DH, Williams TL, Erath SA. The development and validation of the state and trait food-cravings questionnaires. Behavior Therapy. 2001;31(1):151-73.

56. Moreno S, Rodriguez S, Fernandez MC, Tamez J, Cepeda-Benito A. Clinical validation of the trait and state versions of the Food Craving Questionnaire. Assessment. 2008 Sep;15(3):375-87.

57. Vander Wal JS, Johnston KA, Dhurandhar NV. Psychometric properties of the State and Trait Food Cravings Questionnaires among overweight and obese persons. Eating Behav. $2007 ; 8(2): 211-23$.

58. Cappelleri J, Bushmakin A, Gerber R, Leidy N, Sexton C, Lowe M, et al. Psychometric analysis of the Three-Factor Eating Questionnaire-R21: results from a large diverse sample of obese and non-obese participants. Int J Obes. 2009;33(6):611-20.

59. Julia C, Péneau S, Andreeva VA, Méjean C, Fezeu L, Galan P, et al. Weight-loss strategies used by the general population: how are they perceived? PloS one. 2014;9(5):e97834. 
60. Becker H, Stuifbergen AK, Sands D. Development of a scale to measure barriers to health promotion activities among persons with disabilities. American Journal of Health Promotion. 1991;5(6):449-54.

61. Fabbricatore M, Imperatori C, Pecchioli C, Micarelli T, Contardi A, Tamburello S, et al. Binge eating and BIS/BAS activity in obese patients with intense food craving who attend weight control programs. Obes Metab. 2011;7:e21-7.

62. Gearhardt AN, Boswell RG, White MA. The association of "food addiction" with disordered eating and body mass index. Eating Behav. 2014;15(3):427-33.

63. Bertoli S, Leone A, Ponissi V, Bedogni G, Beggio V, Strepparava MG, et al. Prevalence of and risk factors for binge eating behaviour in 6930 adults starting a weight loss or maintenance programme. Public Health Nutr. 2016;19(01):71-7.

64. Linde J, Jeffery R, Levy R, Sherwood N, Utter J, Pronk N, et al. Binge eating disorder, weight control self-efficacy, and depression in overweight men and women. Int J Obes. $2004 ; 28(3): 418-25$.

65. Culbert K, Racine S, Klump K. Hormonal Factors and Disturbances in Eating Disorders. Current Psychiatry Results. 2016;18(7):65.

66. Finzi-Dottan R, Zubery E. The role of depression and anxiety in impulsive and obsessive-compulsive behaviors among anorexic and bulimic patients. Eating disorders. 2009;17(2):162-82.

67. Carvalho-Ferreira JPd, Cipullo MAT, Caranti DA, Masquio DCL, Andrade-Silva SG, Pisani LP, et al. Interdisciplinary lifestyle therapy improves binge eating symptoms and body image dissatisfaction in Brazilian obese adults. Trends in psychiatry and psychotherapy. 2012;34(4):223-33.

68. Andrés A, Saldaña C. Body dissatisfaction and dietary restraint influence binge eating behavior. Nutr Res. 2014;34(11):944-50.

69. Pastore LM, Patrie JT, Morris WL, Dalal P, Bray MJ. Depression symptoms and body dissatisfaction association among polycystic ovary syndrome women. J Psychosom Res. $2011 ; 71(4): 270-6$.

70. Rodino IS, Byrne S, Sanders KA. Obesity and psychological wellbeing in patients undergoing fertility treatment. Reproductive biomedicine online. 2016;32(1):104-12.

71. Innamorati M, Imperatori C, Balsamo M, Tamburello S, Belvederi Murri M, Contardi A, et al. Food Cravings Questionnaire-Trait (FCQ-T) Discriminates Between Obese and Overweight Patients With and Without Binge Eating Tendencies: The Italian Version of the FCQ-T. J Pers Assess. 2014;96(6):632-9.

72. Jarosz PA, Dobal MT, Wilson FL, Schram CA. Disordered eating and food cravings among urban obese African American women. Eating Behav. 2007;8(3):374-81.

73. $\mathrm{Ng} \mathrm{L}$, Davis C. Cravings and food consumption in binge eating disorder. Eating Behav. 2013;14(4):472-5. 
74. Mutsaerts MA, Kuchenbecker WK, Mol BW, Land JA, Hoek A. Dropout is a problem in lifestyle intervention programs for overweight and obese infertile women: a systematic review. Hum Reprod. 2013 Apr;28(4):979-86.

75. DiBonaventura Md, Chapman GB. The effect of barrier underestimation on weight management and exercise change. Psychology, Health and Medicine. 2008;13(1):111-22.

76. Arusoglu G, Koksal G, Cinar N, Tapan S, Aksoy DY, Yildiz BO. Basal and mealstimulated ghrelin, PYY, CCK levels and satiety in lean women with polycystic ovary syndrome: effect of low-dose oral contraceptive. The Journal of Clinical Endocrinology \& Metabolism. 2013;98(11):4475-82.

77. McElroy SL, Guerdjikova AI, Mori N, Munoz MR, Keck PE. Overview of the treatment of binge eating disorder. CNS spectrums. 2015;20(06):546-56.

78. Abiles V, Abiles J, Rodriguez-Ruiz S, Luna V, Martin F, Gandara N, et al. Effectiveness of cognitive behavioral therapy on weight loss after two years of bariatric surgery in morbidly obese patients. Nutr Hosp. 2013 Jul-Aug;28(4):1109-14.

79. Alberts HJ, Mulkens S, Smeets M, Thewissen R. Coping with food cravings. Investigating the potential of a mindfulness-based intervention. Appetite. 2010;55(1):160-3.

80. Hormes JM, Timko CA. All cravings are not created equal. Correlates of menstrual versus non-cyclic chocolate craving. Appetite. 2011;57(1):1-5. 